\title{
BEHAVIOR OF STEEL PLATE-CONCRETE COMPOSITE SHEAR WALL UNDER CYCLIC LOADING
}

\author{
Tadele Ergete Tadesse and Temesgen Wondimu Aure \\ Department of Civil Engineering, College of Architecture and Civil Engineering, Addis Ababa Science and \\ Technology University, Ethiopia, Tel: +251913090655, e-mail: tademan2016@ gmail.com, \\ temesgen.wondimu@aastu.edu.et
}

Received Date: October 19, 2020; Revised Date: July 8, 2021; Acceptance Date: December 15, 2021

\begin{abstract}
Steel-Concrete composite shear wall has become popular recently as it compensates for the disadvantages of concrete and steel plate shear walls and combine the advantage of both. However, there is no detail study that identifies the most critical parameters. This study aims at investigation of steel plate-concrete composite shear wall behavior under cyclic loading with variables such as concrete strength, grade of steel plate, total number of tie constraints and thickness of steel plate. ABAQUS/Standard is used for numerical modeling in this study. As the concrete strength decreases from $86.1 \mathrm{Mpa}$ to $45 \mathrm{Mpa}$, the load capacity declined by $11.76 \%$ and higher stiffness was recorded in specimen with higher grade of concrete. The ductility factor is inversely proportional to grade of concrete from $86.1 \mathrm{Mpa}$ to $60 \mathrm{Mpa}$ which increases from 4.26 to 4.68 and the ductility factor of specimen with $45 \mathrm{Mpa}$ strength is recorded as 3.81 . The energy dissipation capacity is directly proportional to the grade of concrete used. Using high grade steel plate increases the lateral load capacity significantly and exhibited more ductile behavior. Specimen with S355 steel grade exhibited $14.01 \%$ increment of the average load capacity while the specimen with S245 steel grade has shown reduction by $9.21 \%$. Similarly, the ductility factor and energy dissipation capacity of specimen with variable grade of steel are directly proportional. Reduction of tie constraints has no significant effect on the behavior in this study due to high confinement effect of concrete by surrounding steel plate. Specimens with thicker steel plate exhibited good energy dissipation capacity.
\end{abstract}

Keywords: Composite steel plate-concrete shear wall, Compressive damage of concrete, Cyclic loading, High axial load, Tie constraints

\section{Introduction}

\section{Background}

Shear wall is commonly used to resist lateral loads such as wind, earthquake and any vibration in buildings. Shear walls can be classified as reinforced concrete, steel plate and composite shear walls based on their materials. Reinforced concrete walls are inexpensive and stiff while steel members are strong, lightweight and easy to assemble as mentioned by S. Enrico et al., 2004. However, reinforced concrete shear wall is relatively high weight-to-strength ratio compared to steel that can make reinforced concrete shear walls impractical to use for many tall buildings with large shear forces. Zaho et al., 2004, stated that the main disadvantages of reinforced concrete wall are the development of tension cracks in tension zones and compressive crushing in the localized compression areas during large cyclic excursions. Similarly, the main disadvantage of a steel shear wall is the buckling of the compression zone of the wall that results in reduced shear strength, stiffness, and energy dissipation capacity. Steel-Concrete composite shear wall has recently been used material in construction industry for high rise buildings to resist large lateral loads. Construction of such type of combined 
materials offers several advantages such as flexural stiffening, strengthening of compression elements, improved deformability, increased floor area, fire protection, easy repairs and economy as stated by Dan et al., 2011. Steel-Concrete composite shear walls can be classified into two different types depending on the relative position of steel plate and concrete condition such as steel-plate reinforced concrete (SPRC) composite walls and concrete filled double-steel plate (CFSP) composite walls as per studies by Jian-Guo Nie et al., 2013. As per the findings of Kelsen Trista et al., 2020, on Lateral-Torsional Bucking (LTB) of I-shaped steel beam, the LTB resistance of the prismatic I-shaped steel beam (stepped beam) increases from $9.8 \%$ to $202 \%$, which indicates that using steel cover for such element, has advantage.

In this study, concrete filled double-steel plate composite shear wall with boundary members investigated under cyclic lateral loading using finite element software, ABAQUS. Non-linear parametric study has been done following the validation against the experimental report. The simulation model size is similar with the existing experimental model which was $1 / 7$ scale model of the prototype structure. It is important to identify different parameters that critically affect performance of steel-concrete composite shear wall under cyclic loading to apply in the analysis and design for such types of shear wall in building structures analysis and design. Accordingly, analysis for twelve specimens with four variables and each consisting of three specimens done following validation for a control specimen against experimental result.

The main objective of this study is to investigate the behavior of double steel plateconcrete composite shear wall under cyclic loading with nonlinear finite element analysis software, ABAQUS. Further, to Simulate existing experimentally tested composite shear wall model under cyclic loading using nonlinear finite element analysis software, ABAQUS and validate the simulation of the numerical model by comparing the responses such as loaddisplacement relationship and failure modes with the experimental results. Based on validation of the finite element model to establish cyclic behavior for double steel plate-concrete composite shear wall such as load-displacement behavior, damage $\&$ failure modes, stiffness, ductility, energy dissipation capacity and finally to identify the most critical variables which determine the performance of double steel plate-concrete composite shear wall under cyclic loading. In addition to previously investigated behavior of steel-concrete composite shear wall, this study provides useful and further information regarding the considered type of shear wall under loading.

\section{Material and Methodology}

\section{General}

As mentioned in the introduction section of this study, numerical simulation of composite shear wall that is experimentally tested model used to investigate behavior of the stated type of shear wall under cyclic loading with software, ABAQUS. The experimental test conducted by JianGuo Nie et al., 2013, which is published on Journal of Constructional Steel Research with a title "Experimental Study on Seismic Behavior of High Strength Concrete Filled Double Steel Plate Composite Walls" is used for validation of simulation and further investigation with variables.

The considered composite shear wall consists of concrete filled steel tubular columns at the two boundaries and concrete filled double steel plate wall body and divided into compartments by vertical stiffeners transversally connected by distributed batten plates as shown in Figure 1. To create full interaction of concrete and steel plate of the composite shear wall, $30 \mathrm{~mm}$ studs at $107 \mathrm{~mm}$ spacing are welded on the surface of steel plate which are simulated in the numerical model by tie constraint and the simulation of the model is as shown in Figure 2. 


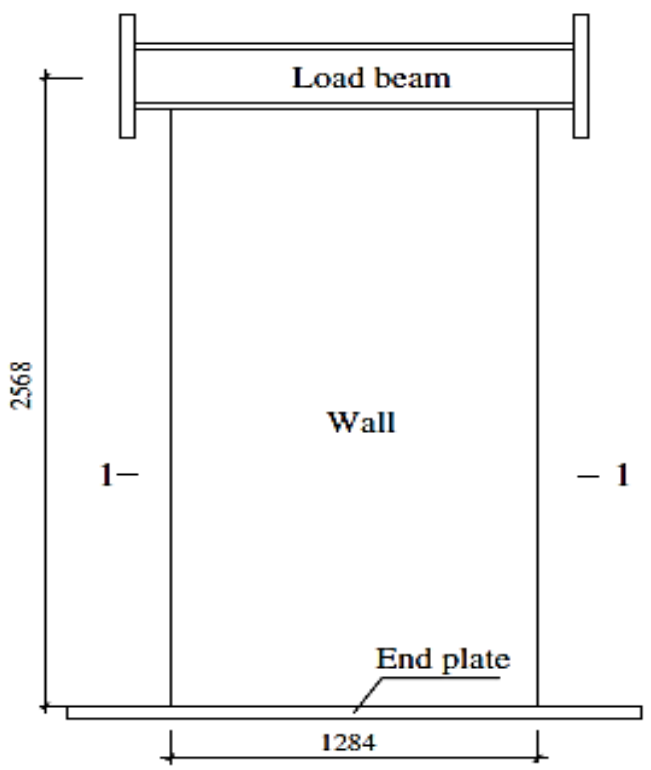

a) Front view

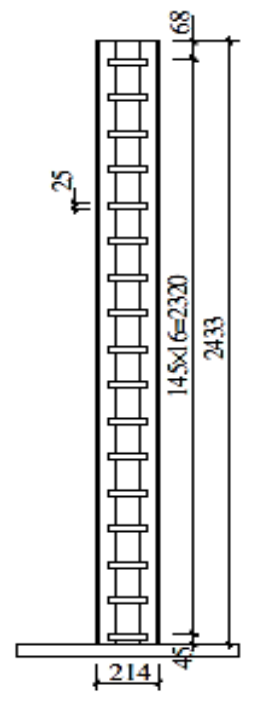

c) 2-2 Section

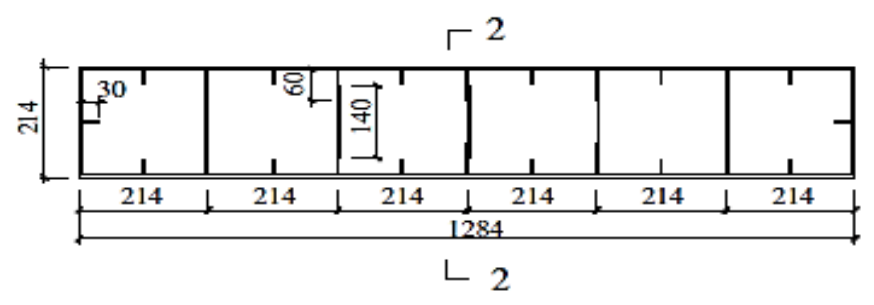

b) 1-1 Section

Figure 1. Detail of CFSCW (Jian-Guo Nie et al., 2013, all dimensions are in mm)

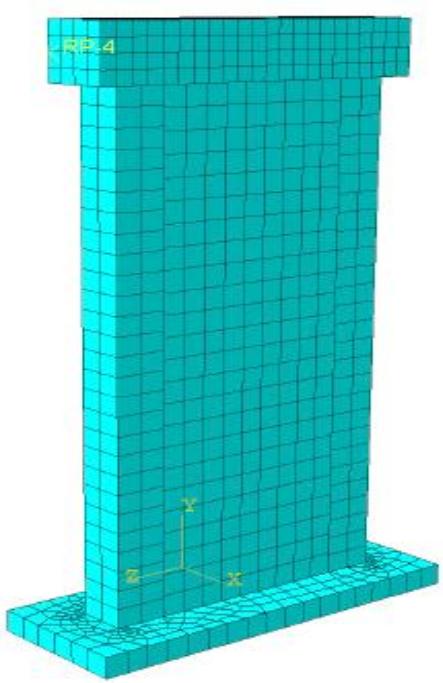

a) Elevation

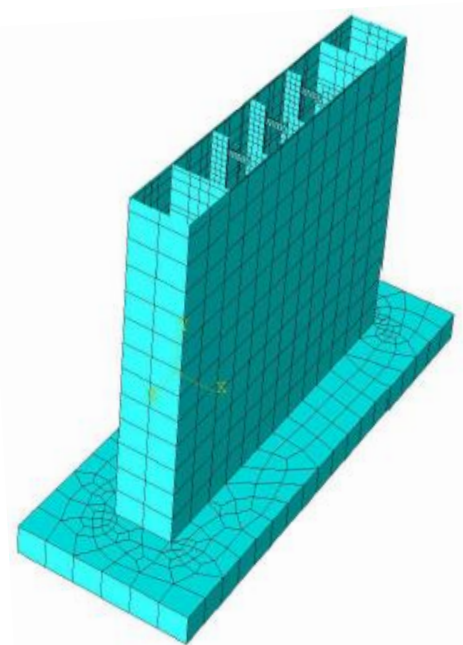

(b) Section

Figure 2. Numerical model of composite shear wall 


\section{Description of Numerical Modelling for This Study}

The specimens in this study were classified into four groups and each has three different specimens which is 12 specimens were considered for the parametric study as described in the next section. Four variables were considered in this study such as concrete strength, grade of steel plate, total number of tie constraints used between steel and concrete to create composite action as studs in the experimental models and thickness of steel plate. The reason to select the mentioned parameters in this study is that failures of such composite shear wall are due to the failure of components as stated by different researchers of similar works as Zaho et al., 2004. The summary of the specimens for all groups is presented in Table 1.

Table 1. Summary of Specimens for the FEA

\begin{tabular}{|c|c|c|c|c|c|c|}
\hline Group & Specimen & $\begin{array}{l}\text { Wall Cross- } \\
\text { Section } \\
(\mathbf{m m} \times \mathbf{~ m m})\end{array}$ & $\begin{array}{c}\text { Grade of } \\
\text { Concrete } \\
\text { (MPa) }\end{array}$ & $\begin{array}{c}\text { Grade of } \\
\text { Steel } \\
\text { Plate }\end{array}$ & $\begin{array}{c}\text { Total } \\
\text { Number of } \\
\text { Tie } \\
\text { Constrains } \\
\end{array}$ & $\begin{array}{c}\text { Thickness } \\
\text { of Steel } \\
\text { Plate }(\mathbf{m m})\end{array}$ \\
\hline Control & CFSCW & $1284 \times 214$ & 86.1 & S275 & 832 & 5 \\
\hline 1 & $\begin{array}{l}\text { GS11-C70 } \\
\text { GS11-C60 } \\
\text { GS11-C45 }\end{array}$ & $\begin{array}{l}1284 \times 214 \\
1284 \times 214 \\
1284 \times 214\end{array}$ & $\begin{array}{l}70 \\
60 \\
45\end{array}$ & S275 & 832 & 5 \\
\hline 2 & $\begin{array}{l}\text { GS21-S355 } \\
\text { GS22-S265 } \\
\text { GS23-S245 }\end{array}$ & $\begin{array}{l}1284 \times 214 \\
1284 \times 214 \\
1284 \times 214\end{array}$ & 86.1 & $\begin{array}{l}\text { S355 } \\
\text { S265 } \\
\text { S245 }\end{array}$ & 832 & 5 \\
\hline 3 & $\begin{array}{l}\text { GS31-TC640 } \\
\text { GS32-TC440 } \\
\text { GS23-TC248 }\end{array}$ & $\begin{array}{l}1284 \times 214 \\
1284 \times 214 \\
1284 \times 214\end{array}$ & 86.1 & S275 & $\begin{array}{l}640 \\
440 \\
248\end{array}$ & 5 \\
\hline 4 & $\begin{array}{c}\text { GS41-ST6.5 } \\
\text { GS42-ST4 } \\
\text { GS43-ST3 }\end{array}$ & $\begin{array}{l}1284 \times 214 \\
1284 \times 214 \\
1284 \times 214\end{array}$ & 86.1 & S275 & 832 & $\begin{array}{c}6.5 \\
4 \\
3\end{array}$ \\
\hline
\end{tabular}

\section{Material Modelling}

The numerical material modeling of the components of composite shear wall executed based on the options available in the software, ABAQUS. The basic material properties of concrete and steel mentioned in the experimental test were used in component material model of the finite element analysis. Beside to the geometrical nonlinearity, material nonlinearity was considered during analysis of the numerical models in this study.

Different researchers have been exercising numerical simulation of shear wall based on experimental and theoretical backgrounds. Vacchio et al., 2011, applied the Distributed Stress Field Model; smeared rotating crack models for reinforced concrete based on the Modified Compression Field Theory, to the analysis of steel and concrete wall elements under axial and shear loads. Validation for their studies undertaken by arranging various test specimens, including panel elements subject to uniaxial compression, panel elements subjected to in-plane shear, and wall specimens subjected to reversed cyclic lateral displacements.

Jianbao Li et al., 2012, has developed numerical simulation of laminated reinforced concrete shear wall with ABAQUS software and the report has good agreement with the experimental test results. The damage plasticity concrete model chosen for concrete material 
component, Kent-Park concrete model for compressive Stress-Strain relationship applied, and Kang Lin model for concrete tensile behavior is used. C3D8R \& T3D2 element types applied for concrete \& rebar respectively and bond spring unit considered in between the two materials. The results of the simulation compared with the experimental tests such as damage \& failure modes, displacement-load curves and similar characters reported.

\section{Concrete Material Modelling}

Concrete damaged plasticity model was applied in this study for its general capability for modeling concrete behavior in all types of structures (beams, trusses, shells, and solids) as it is stated in ABAQUS analysis user's guide part V. The model is a continuum, plasticity-based, damage model for concrete. It assumes that the main two failure mechanisms are tensile cracking and compressive crushing of the concrete material. The evolution of the yield (or failure) surface controlled by two hardening variables, $\tilde{\varepsilon}_{t}^{p l}$ and $\tilde{\varepsilon}_{c}^{p l}$, linked to failure mechanisms under tension and compression loading respectively as mentioned in the user's guide.

Based on experimental data of concrete material properties and confined concrete under compressive load model suggested by K. Susantha et al., 2001 stress-strain relationship was developed. The calculated confined concrete material properties and stress-strain behavior under compressive loading are presented in Table 2 and Figure 3 respectively.

\section{Table 2. Summary of Calculated Concrete Material Properties}

\begin{tabular}{cccccc}
\hline $\begin{array}{l}\text { Material } \\
\text { Property }\end{array}$ & $\mathrm{f}_{\mathrm{c}}^{\prime}(\mathrm{MPa})$ & $\mathrm{e}_{\mathrm{co}}$ & $\mathrm{E}_{\mathrm{c}}(\mathrm{MPa})$ & $\mathrm{f}_{\mathrm{cc}}^{\prime}(\mathrm{MPa})$ & $\mathrm{e}_{\mathrm{cu}}$ \\
\hline Value & 71.65 & 0.00235 & 34896.534 & 73.78 & 0.018 \\
\hline
\end{tabular}

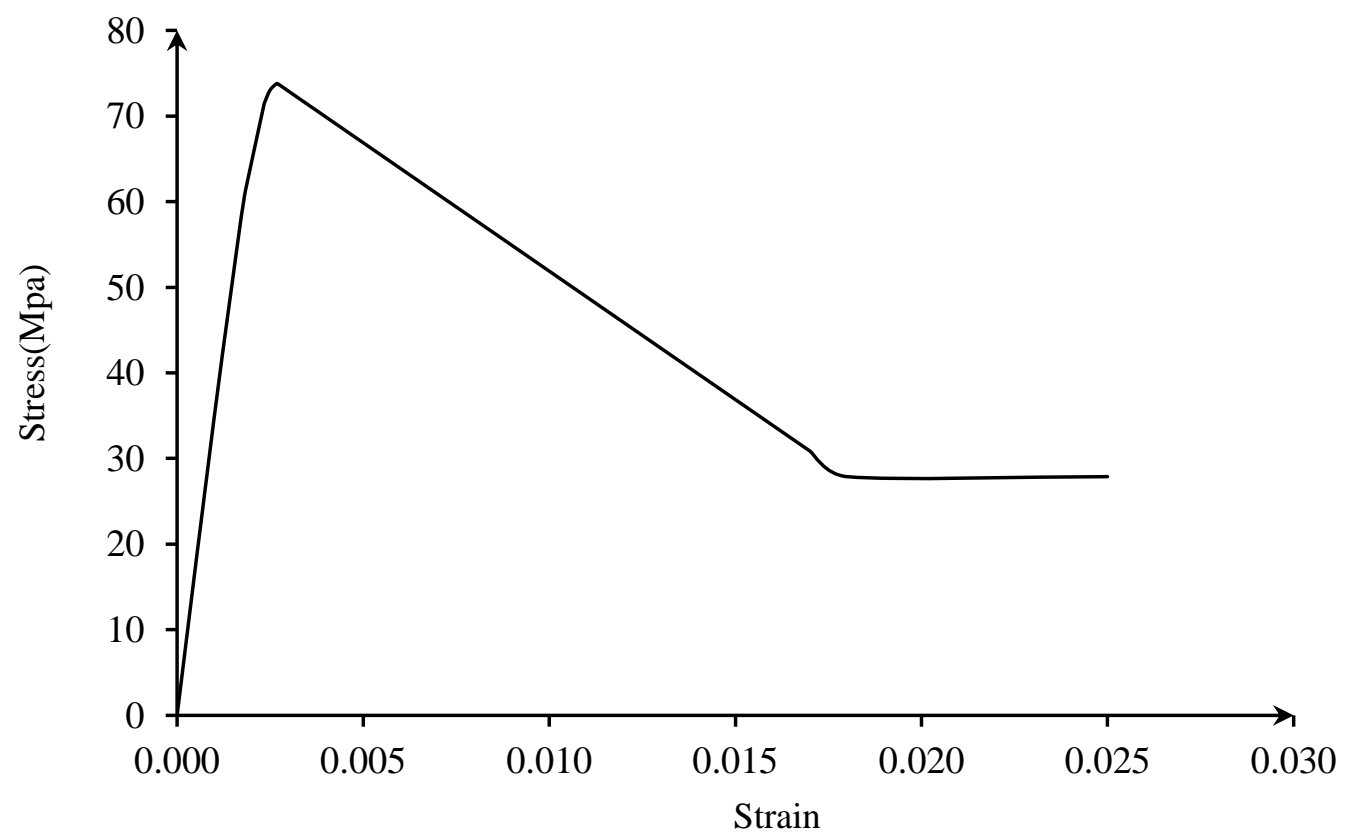

Figure 3. Stress-strain curve for confined concrete in compression 
Similarly, the stress-strain relation for concrete in tension was prepared based on model proposed by A. Belarbi and T. Hsu, 1994, as shown in Figure 4. The accuracy of material model used for the numerical analysis is crucial for the exact simulation of the experimental test. Accordingly, material modeling of concrete was done carefully to get better simulation of the experimental test with acceptable error.

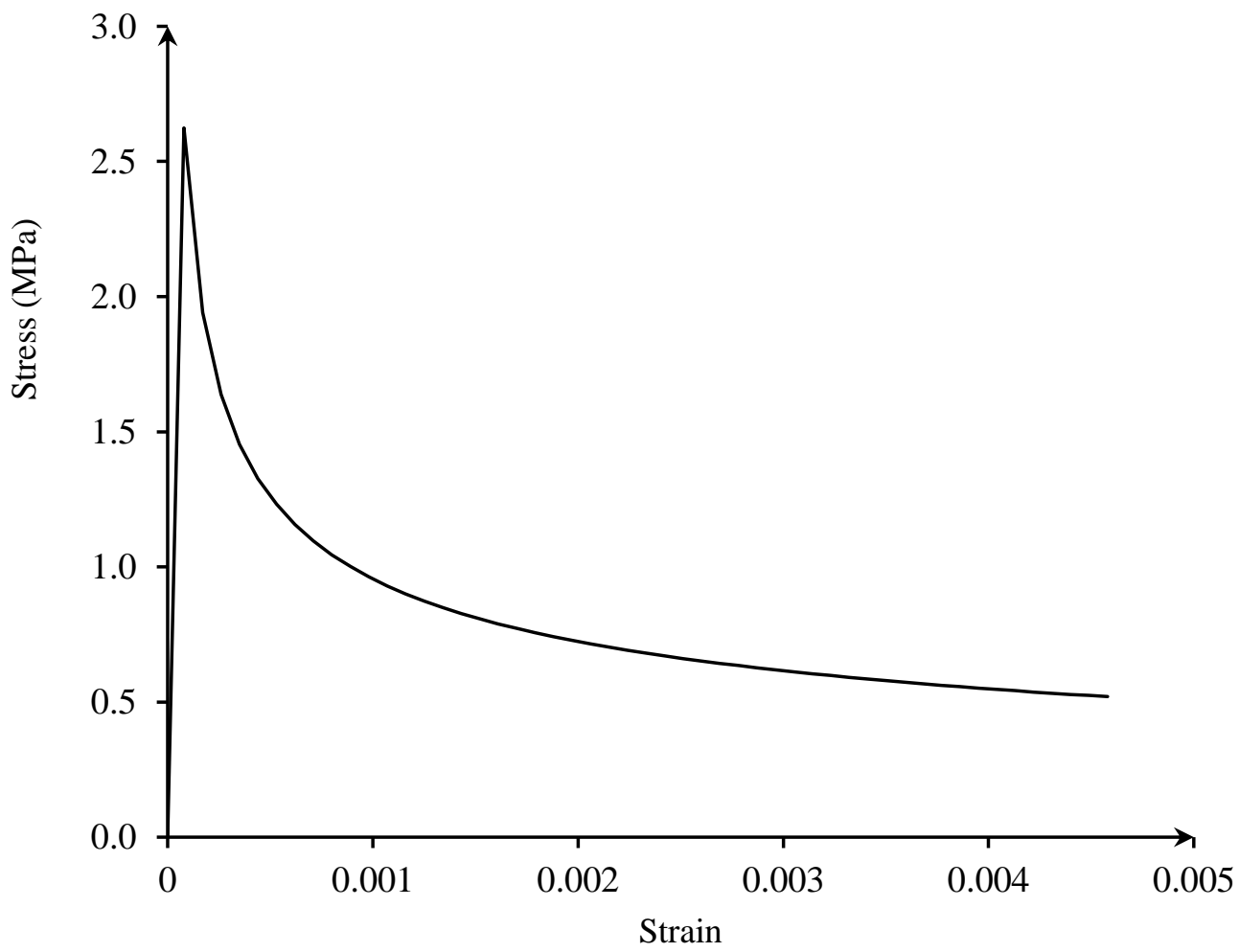

Figure 4. Stress-Strain relationships for concrete in tension

\section{Steel Material Modelling}

Nonlinear isotropic/Kinematic hardening model applied for steel material model in the software, ABAQUS. The evolution law of this model consists of two components such as the kinematic hardening components, which describes the translation of the yield surface in stress space through the back stress, $\alpha$; and an isotropic hardening component, which describes the change of the equivalent stress defining the size of the yield surface, $\sigma^{\circ}$, as a function of plastic deformation.

The stress-strain relation for steel material was prepared based on fundamental properties of steel material used in the experimental test with modification and a model suggested by Y. Shi et al., 2011, which is presented in Table 3 and Figure 5. The nominal (Engineering) stress-strain from experimental testing was converted to true stress \& logarithmic strain to consider the instantaneous section of steel plate using the following relationship:

$$
\begin{gathered}
\delta_{\text {true }}=\delta_{\text {nom }}\left(1+\varepsilon_{\text {nom }}\right) \\
\varepsilon_{l n}^{p l}=\ln \left(1+\varepsilon_{\text {nom }}\right)-\frac{\delta_{\text {true }}}{E}
\end{gathered}
$$


Table 3. Fundamental Properties of Steel Material

\begin{tabular}{cccc}
\hline $\begin{array}{c}\text { Material } \\
\text { Property }\end{array}$ & $\begin{array}{c}\text { Yield } \\
\text { Stress }\left(\mathbf{N} / \mathbf{m m}^{\prime \prime}\right)\end{array}$ & $\begin{array}{c}\text { Elastic Modulus } \\
\left(\mathbf{N} / \mathbf{m m}^{2}\right)\end{array}$ & $\begin{array}{c}\text { Poisson's } \\
\left.\text { Ratio(N/mm } \mathbf{m}^{2}\right)\end{array}$ \\
\hline Value & 285 & 207000 & 0.3 \\
\hline
\end{tabular}

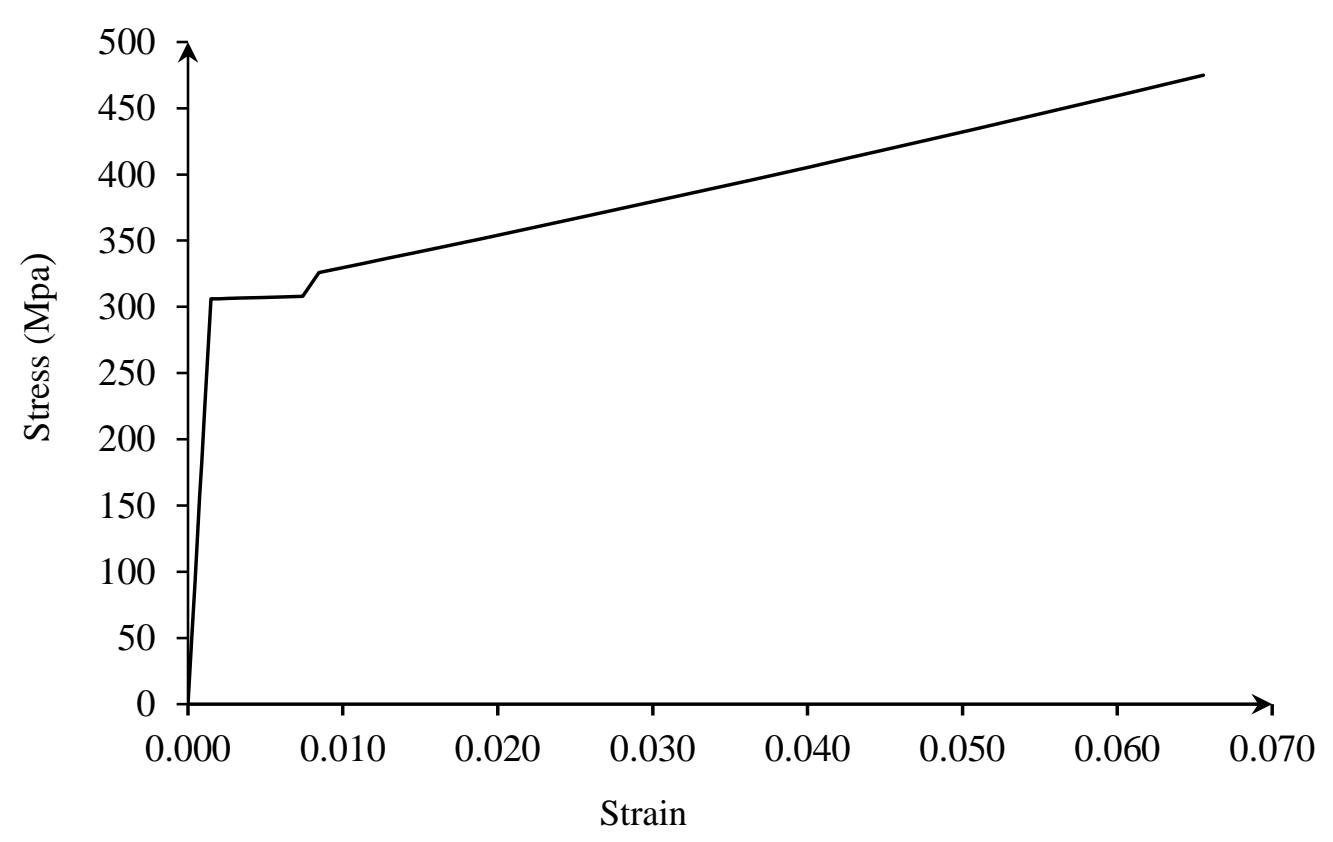

Figure 5. Stress-strain relationship for steel

\section{Section Properties, Element Types and Interaction of Parts}

\section{Section Properties}

The material properties for each section were assigned by defining material property as concrete material, steel plate and rigid steel in material property module of the software, ABAQUS. Concrete and steel material properties were modeled under Material Modelling section, and rigid steel material is simply assumed as a rigid material considering a higher modulus of elasticity which is used only to transfer and distribute load (load beam) at top to the composite shear wall as well as at the support (end plate) with negligible deformation which are not the main parts of the analysis. The type of section and material of each section is summarized in Table 4.

Table 4. Section and Materials Used in the FEA Model

\begin{tabular}{clc}
\hline Section Name & \multicolumn{1}{c}{ Type } & Material \\
\hline Concrete section & Solid, homogeneous & Concrete \\
\hline Steel Plate Section & Shell, homogeneous & Steel \\
\hline Rigid section & Solid, homogenous & Steel \\
\hline
\end{tabular}




\section{Element Types}

Accuracy of the analysis result also depends on the element type and size; accordingly, necessary attention was given for the same. The components of the composite shear wall with element type and size presented in Table 5. The optimum size of elements for each component is formulated by trial and error as well as the element types are created by considering the recommendations of ABAQUS user's manual.

Table 5. Element Type and Size of Components

\begin{tabular}{ccc}
\hline Component & Element Type & Mesh Size \\
\hline Concrete wall & C3D8R & 80 \\
\hline Concrete column & C3D8R & 70 \\
\hline Wall plate & S4R & 100 \\
\hline Column tubes & S4R & 90 \\
\hline Stiffeners & S4R & 20 \\
\hline batten plates & S4R & 10 \\
\hline Load beam & C3D8R & 70 \\
\hline End Plate & C3D8R & 100 \\
\hline
\end{tabular}

\section{Interaction of Parts}

Interaction between parts was created as contact and constraints between surfaces/nodes of parts. In ABAQUS analysis user's guide, contact definition is generally described as two surfaces that may interact with each other as a "contact pair" or in terms of a single surface that may interact with itself in "self-contact". In this study contact pairs were created by defining the mechanical and geometrical assignment for each contact pairs. Different types of constraint interactions are available in ABAQUS/CAE to constrain surfaces/nodes or any other part of assembled model used to correctly simulate the relationship in between. In this study tie constraint, embedded constraint and coupling constraint were utilized between components and reference points to simulate the experimentally tested model.

\section{Loading and Boundary Conditions}

\section{Loading Condition}

Loading in the numerical study was done in similar steps to the experimental test to simulate the actual condition and to observe the effects at different drift ratios of the composite shear wall. Three steps were created to apply loads by considering geometrically nonlinear behavior, static for all with default automatic stabilization and automatic incrementation. Static vertical load of $5000 \mathrm{KN}$ was first applied through the first step at a reference point which is constrained with the top surface of load beam using structural coupling to distribute the load as shown in Figure 7. In the second step, load controlled cyclic loading was created and applied by defining amplitude (Amp-1) of lateral concentrated load at a reference point until the composite shear wall attains $1 / 400$ drift ratio as it is stated in the experimental report. Finally, in the third step, displacement controlled cyclic loading was created as a boundary condition with predefined amplitude (Amp-2) at a reference point shown in Figure 7. The lateral loading procedure applied in the numerical model is similar to the experimental loading procedure as shown in Figure 6. 


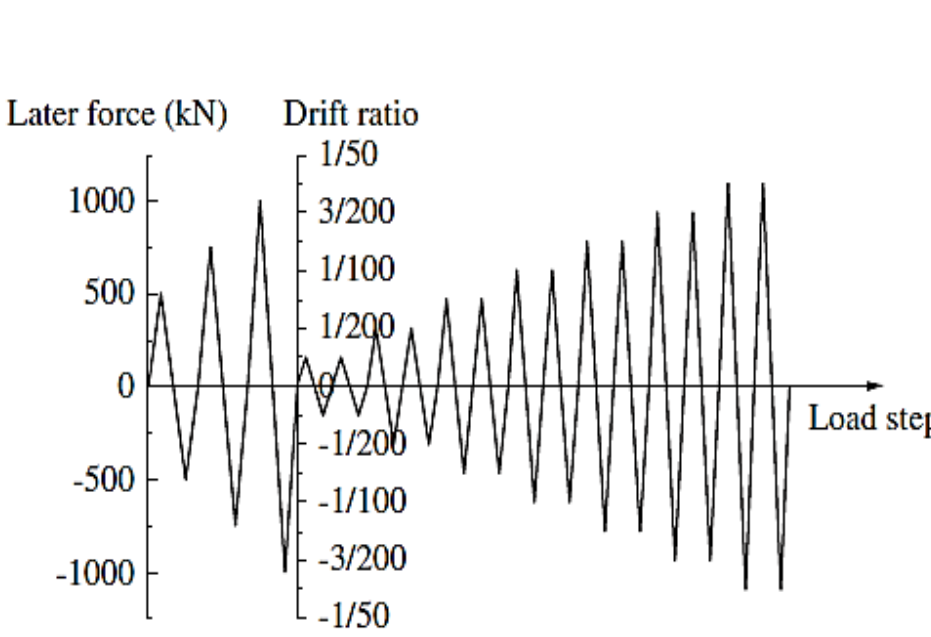

Figure 6. Lateral loading procedure

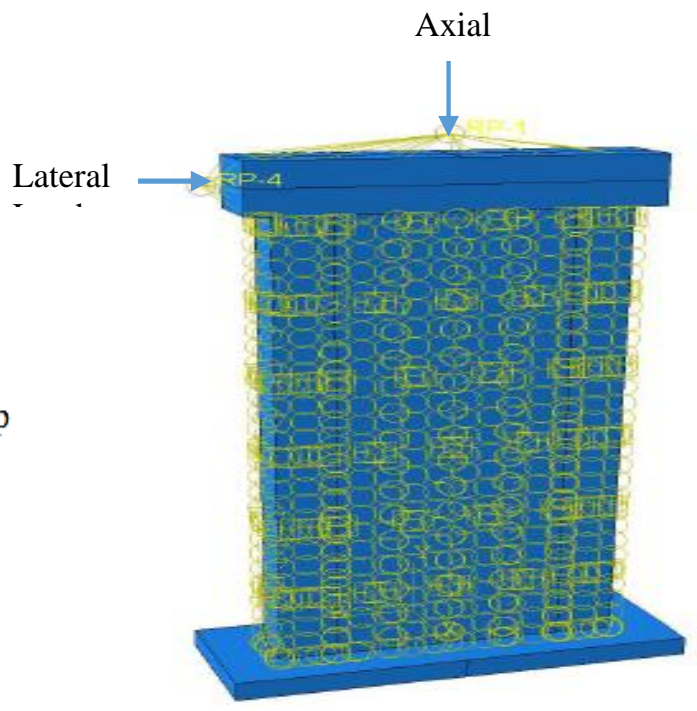

Figure 7. Applied loads

\section{Boundary Condition}

The translations in all direction (X, Y, and Z) of the composite shear wall at the bottom of the concrete and steel components were constrained and free rotation in all direction at the bottom of the wall is considered. All DOF are restrained at the bottom surface of end plated to simulate rigid support to the composite shear wall of the existing experimental model.

\section{Analysis}

The analysis of the composite shear walls in this study considers the nonlinearity of the materials used which are defined in property module and geometrical nonlinearity with general static procedure defined in step module of the software. The solution technique used for the analysis is full Newton with automatic and large maximum incrimination to allow the software a wide range for the completion of the analysis. Finally, full analysis was run for predefined field output by submitting a job for the created model in job module of ABAQUS software using a desktop computer with 64bit operating system, 3GHz, 8GB RAM.

\section{Results and Discussion}

\section{Validation of Numerical Model}

Validation of finite element model is the first step and necessary to further investigate behavior of a model with acceptable accuracy through comparing with existing experimental models. The numerical model was verified by comparing the load-displacement behavior and the failure modes with the experimental test in the following subsections.

\section{Load-Displacement Behavior}

Here, finite element analysis of concrete filled steel composite shear wall is compared with the existing experimental test results with respect to the load-displacement response in the hysteretic and envelope curves as shown in Figures 8 and 9. The average maximum load (both directions of cycles) of the finite element analysis result is $5.8 \%$ lower than the experimental test result. The picks of the FEA and experimental hysteric curves are very close to each other as can be seen in Figure 8. Hence, the load-displacement behavior of the FEA is closely simulated the corresponding behavior of the experimental model. 


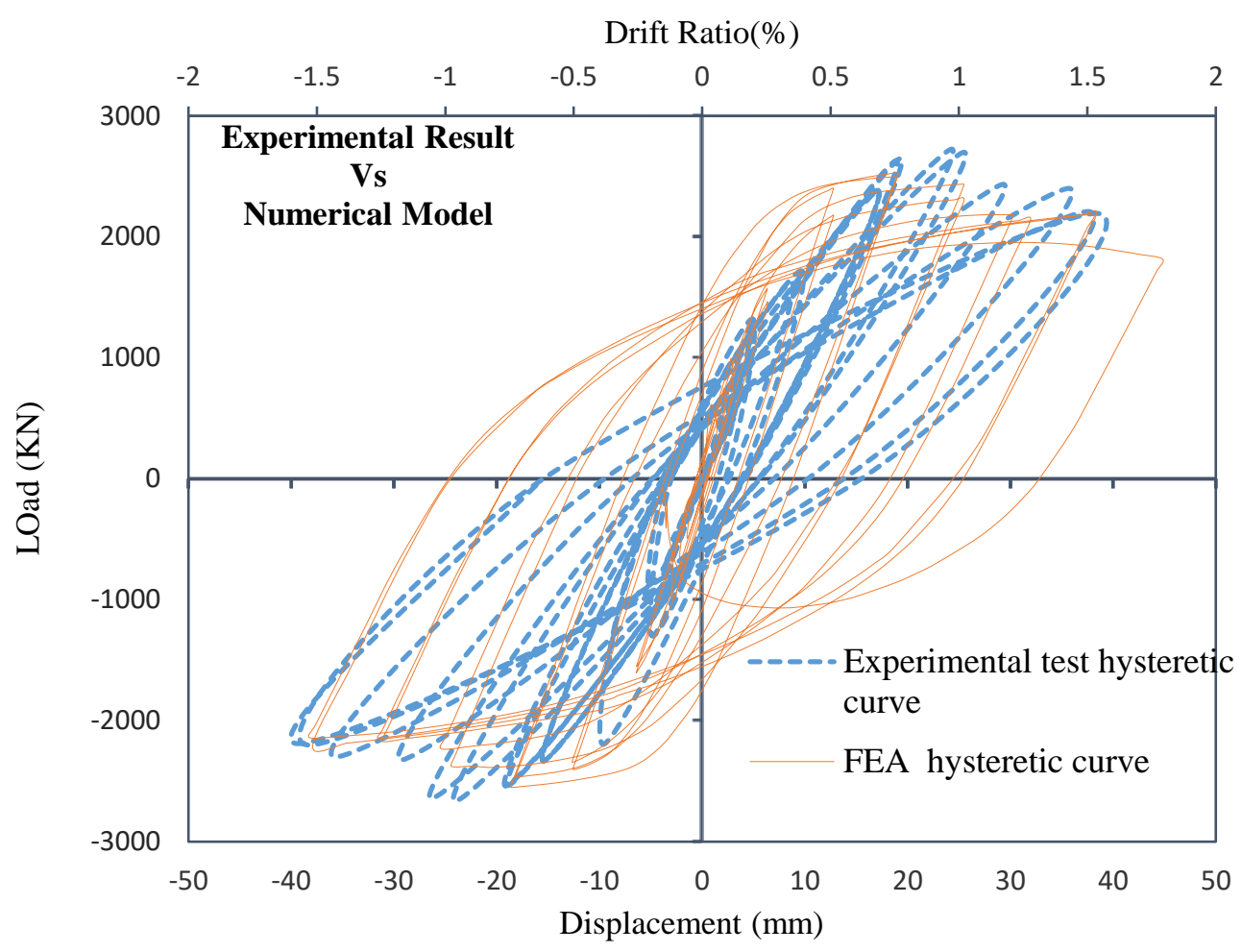

Figure 8. Load-displacement hysteretic curve

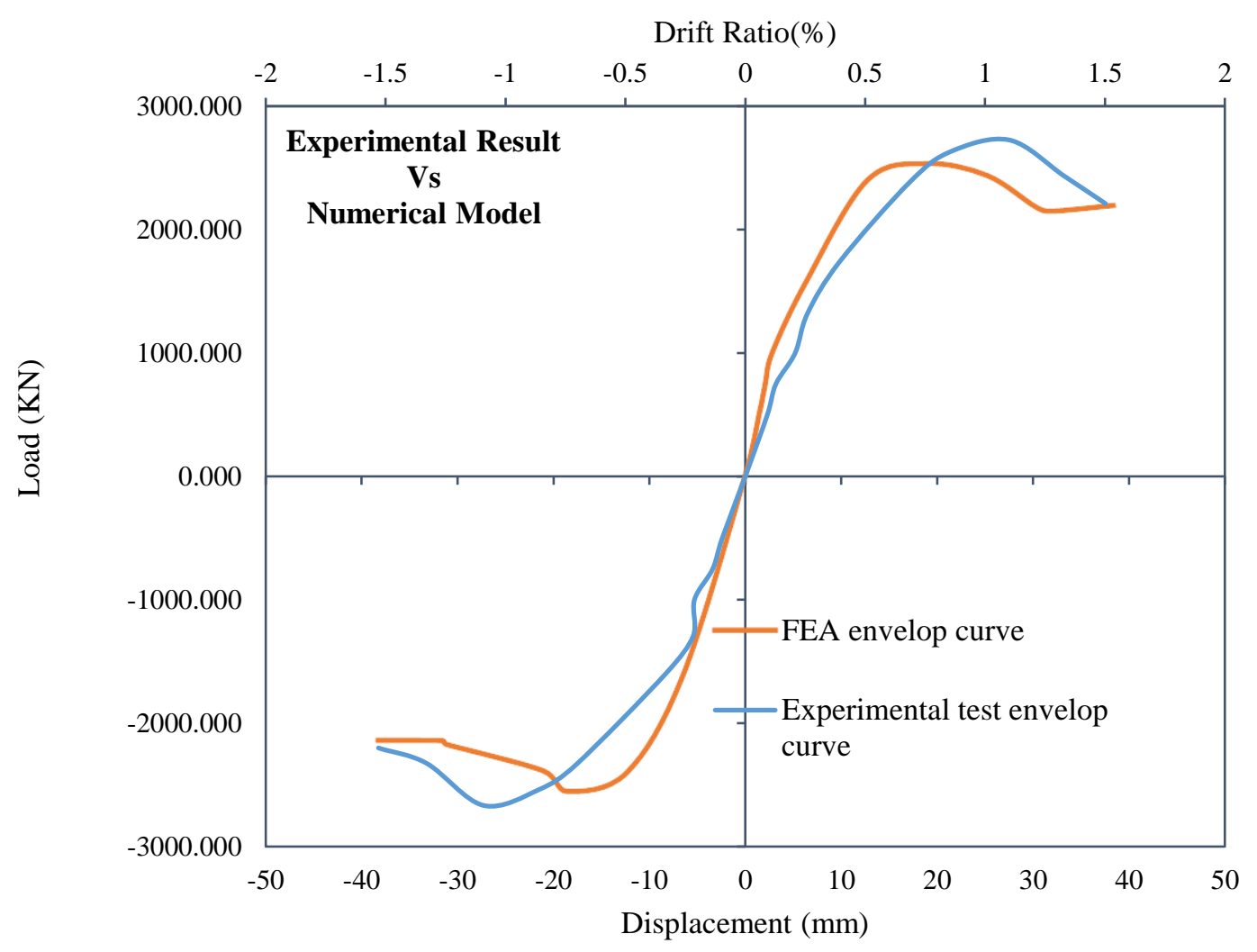

Figure 9. Load-displacement envelop curve 
The accuracy of the FEA model relative to the experimental test result is done by comparing their respective average maximum load using the following simple equation:

$$
\text { Accuracy of FEA model }(\%)=\frac{\text { FEA model result }}{\text { Experimental test result }} * 100
$$

Error of numerical modeling of existing experimental model can be calculated using equation 4.2.

$$
\text { Error }(\%)=\frac{\text { FEA model result-Experimental test result }}{\text { Experimental test result }} * 100 \%
$$

Yielding load is one important behavior in structure which is a load beyond that a material or structure deform permanently after removing the applied load. Accordingly, the average yielding load of the FEA model and experimental model are compared as $2399.2 \mathrm{KN}$ and $2359.5 \mathrm{KN}$ respectively as well as the average maximum load of finite element analysis and the experimental test result are $2541.18 \mathrm{KN}$ and $2696.5 \mathrm{KN}$ respectively considering both directions of the lateral cyclic loading. Hence, with the above Equation 3 and 4, the accuracy and error of the numerical model with respect to existing experimental model are presented in Table 5.

\begin{tabular}{|c|c|c|c|c|c|c|}
\hline Model & $\begin{array}{c}\text { Average } \\
\text { Yielding } \\
\text { Load (KN) }\end{array}$ & $\begin{array}{c}\text { Accuracy } \\
(\%)\end{array}$ & $\begin{array}{c}\text { Error } \\
(\%)\end{array}$ & $\begin{array}{c}\text { Average } \\
\text { Maximum } \\
\text { Load (KN) }\end{array}$ & $\begin{array}{c}\text { Accuracy } \\
(\%)\end{array}$ & $\begin{array}{c}\text { Error } \\
(\%)\end{array}$ \\
\hline FEA & 2399.22 & \multirow{2}{*}{101.7} & \multirow{2}{*}{1.7} & 2541.18 & \multirow{2}{*}{94.2} & \multirow{2}{*}{-5.8} \\
\hline Experimental & 2359.50 & & & 2696.50 & & \\
\hline
\end{tabular}

Table 5. Yielding and Maximum Load Comparison of FEA Model with Experimental Test

As can be seen the results in Table 5, the average yielding load and the average maximum load of the finite element analysis show good agreement with the experimental test results with acceptable error of $1.7 \%$ and $-5.8 \%$ respectively. Similarly, the displacement of the numerical model at top of the shear wall is very close to the experimental drifts applied.

\section{Modes of Failure}

Failure modes of the Finite Element Model are compared with the Experimental Test to further investigate the accuracy of the numerical model and good similarities was observed, as shown in Figures 10, which indicates that highly fractured and yield steel surface at the toe of boundary elements (columns) as well as initially the concrete had no damage due to its high compressive strength. However, after repeated cyclic loading, the concrete at the toe of the composite shear wall is crushed as expected and similar to the experimental test. This additional evidence proves the accuracy of the numerical model and decided to proceed to the next parametric study. 

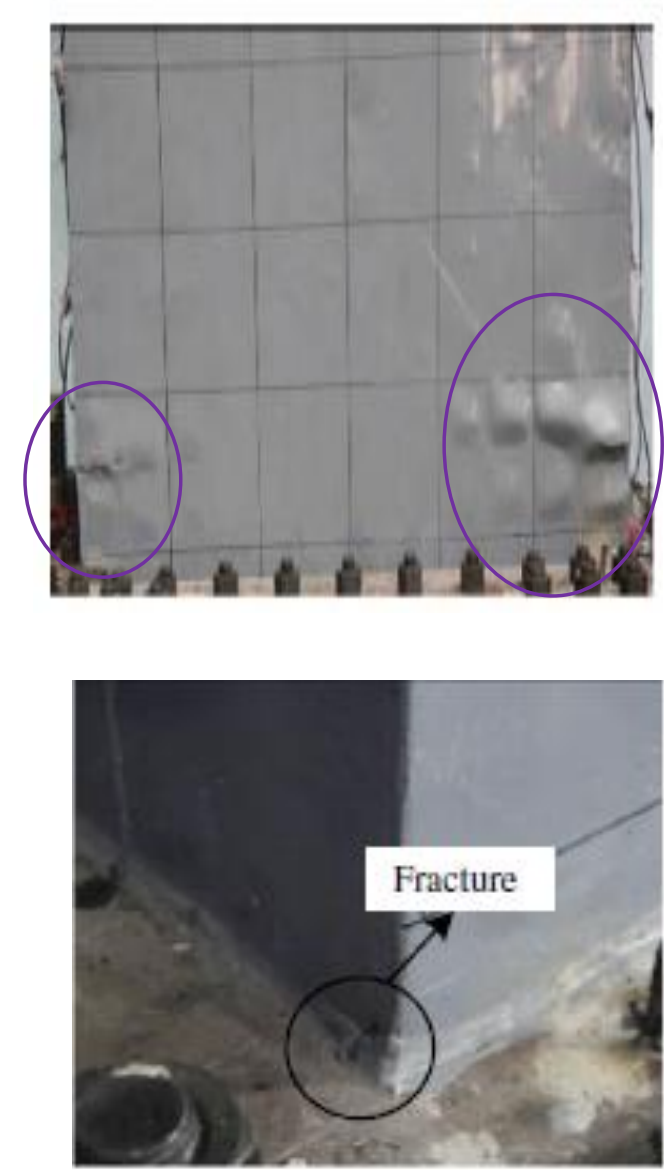

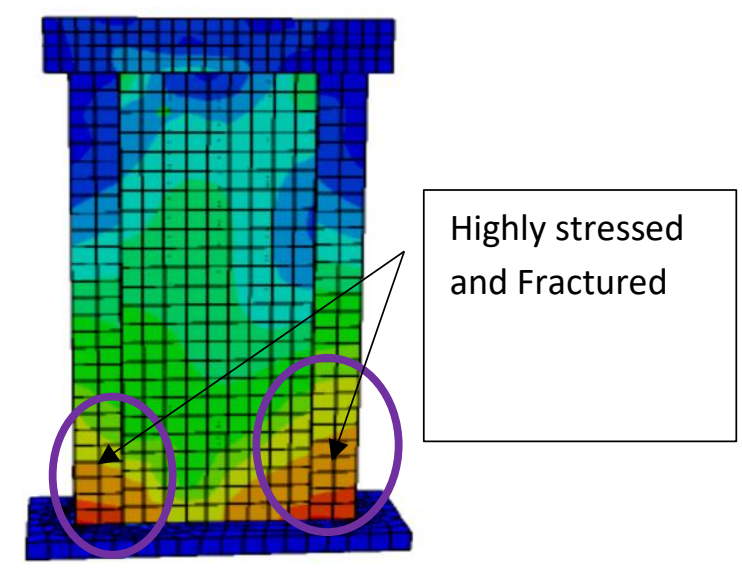

S, Mises fraction $=-0.774$ (Avg: $75 \%$ )

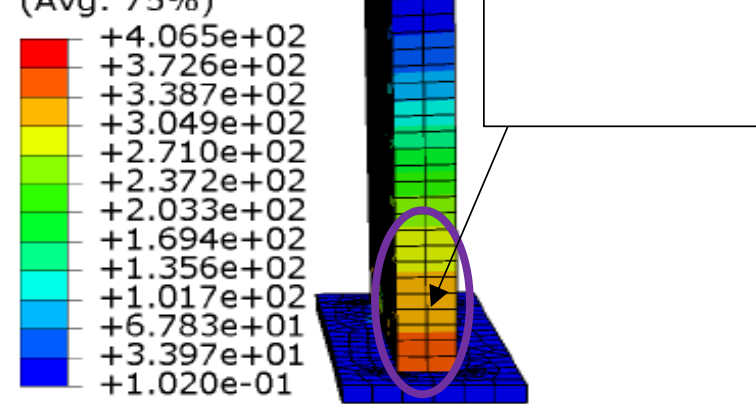

a) Experimental (Jian-Guo Nie et al., 2013)

(b) Numerical Model

Figure 10. Comparison of Experimental and Numerical model failure modes

\section{Discussions}

Here in this section of the study, discussions such as load-displacement response, damage and failure modes, stiffness degradation, ductility behavior and energy dissipation capacity of all composite shear wall specimens are presented in the following subsections.

\section{Load-Displacement Behavior}

Load carrying capacity of the composite shear wall varies due to the effect of different grade of concrete used for each specimen. Specimen with higher grade of concrete exhibited higher load capacity and vice versa relatively. Similarly, grade of steel used in composite shear wall has significant effect in load carrying capacity. The GS21-S355 specimen show highest average maximum load capacity from the group as well as higher than the control specimen with significant difference due to highest steel grade used. This indicates that the grade of steel used in composite shear wall has very significant effect in the load capacity behavior of steelconcrete composite shear walls.

The third group of specimens with varied parameter of total tie constraints (studs) has no much difference in load carrying capacity within the group. However, there is difference between highly constrained composite shear wall, which is the control specimen and less constrained composite shear wall (GS33-TC248). 
Finally, composite shear walls with thick steel plate has shown higher capacity and thin steel plate has less load capacity relatively as expected. The relative evaluation of loaddisplacement behavior of all specimens is summarized and presented in Table 6 to see overall effect of varied parameters of specimens on load capacity and drift ratios as compared to the control specimen.

Table 6. Maximum Loads and Drift Ratio of All Specimen and Comparison with Control Specimen

\begin{tabular}{|c|c|c|c|c|c|c|}
\hline \multirow{2}{*}{ Specimen } & \multicolumn{2}{|c|}{$\begin{array}{c}\text { Max. Load } \\
(\mathrm{KN})\end{array}$} & \multirow{2}{*}{$\begin{array}{c}\text { Average } \\
\text { Max. } \\
\text { Load } \\
(\text { KN) }\end{array}$} & \multicolumn{2}{|c|}{$\begin{array}{c}\text { Drift Ratio at } \\
\text { Max. Load (\%) }\end{array}$} & \multirow{2}{*}{$\begin{array}{c}\text { Average Change } \\
\text { in Load Capacity } \\
(\%)\end{array}$} \\
\hline & $(+)$ & $(-)$ & & $(+)$ & $(-)$ & \\
\hline Control & 2531.20 & 2551.15 & 2541.18 & 0.74 & 0.72 & - \\
\hline GS11-C70 & 2342.46 & 2321.57 & 2332.02 & 0.75 & 0.75 & -8.23 \\
\hline GS 12-C60 & 2283.16 & 2273.17 & 2278.17 & 0.75 & 0.75 & -10.35 \\
\hline GS13-C45 & 2244.26 & 2240.19 & 2242.23 & 0.97 & 0.70 & -11.76 \\
\hline GS21-S355 & 2902.94 & 2891.21 & 2897.08 & 1.00 & 1.00 & 14.01 \\
\hline GS22-S265 & 2390.34 & 2414.63 & 2402.49 & 0.75 & 0.74 & -5.46 \\
\hline GS23-S245 & 2311.37 & 2302.86 & 2307.12 & 0.99 & 0.73 & -9.21 \\
\hline GS31-TC640 & 2485.17 & 2483.74 & 2484.46 & 0.74 & 0.72 & -2.23 \\
\hline GS31-TC440 & 2476.76 & 2471.48 & 2474.12 & 0.74 & 0.74 & -2.64 \\
\hline GS31-TC248 & 2450.65 & 2460.52 & 2455.69 & 0.74 & 0.73 & -3.36 \\
\hline GS41-ST6.5 & 2593.86 & 2538.44 & 2566.15 & 0.74 & 0.73 & 0.98 \\
\hline GS42-ST4 & 2466.23 & 2408.85 & 2437.54 & 0.72 & 0.75 & -4.10 \\
\hline GS43-ST3 & 2447.52 & 2387.12 & 2417.32 & 0.72 & 0.73 & -4.87 \\
\hline
\end{tabular}

\section{Damage and Failure Modes of Specimens}

Here in this section of the study, damage and failure modes of a GS11-C70 specimen is presented for illustration only to show the damage of materials of the composite shear wall at different drift ratio as a sample. The compressive damage of concrete at $0.25 \%$ drift ratio is insignificant while the tensile damage is significant at certain sections of the concrete as shown in Figure 11. 


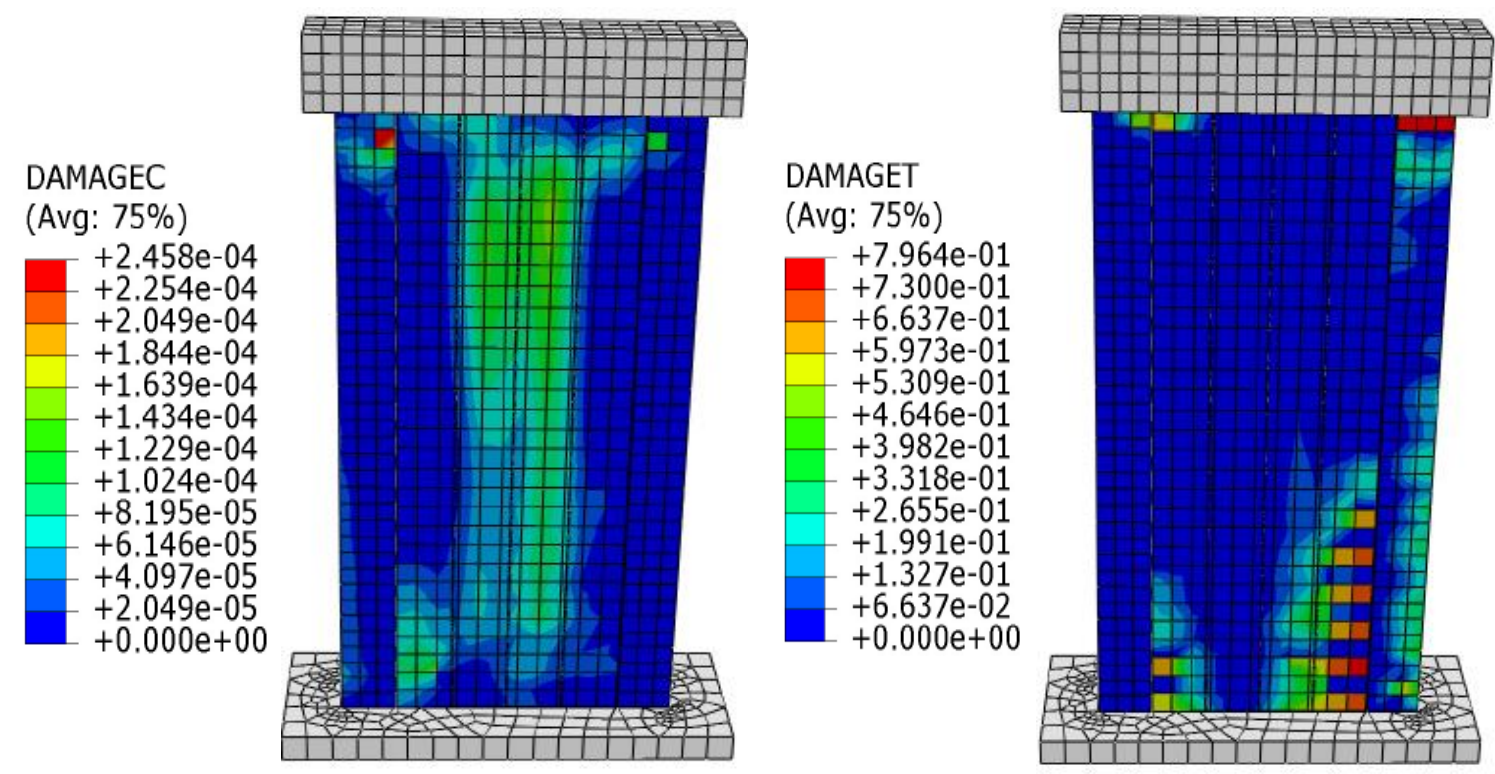
a) Compressive damage of Concrete
b) Tensile damage of Concrete

Figure 11. Damage of concrete at $0.25 \%$ drift ratio of GS11-C70 Specimen

The Von Mises stress of the composite shear wall increases as the drift ratio increases from $0.25 \%$ to $0.75 \%$ with wider contour of higher stress at the toe of the boundary and middle wall section and the compressive damage of concrete at $0.75 \%$ is higher at the bottom of the middle part of the composite shear wall as shown in Figure 12.

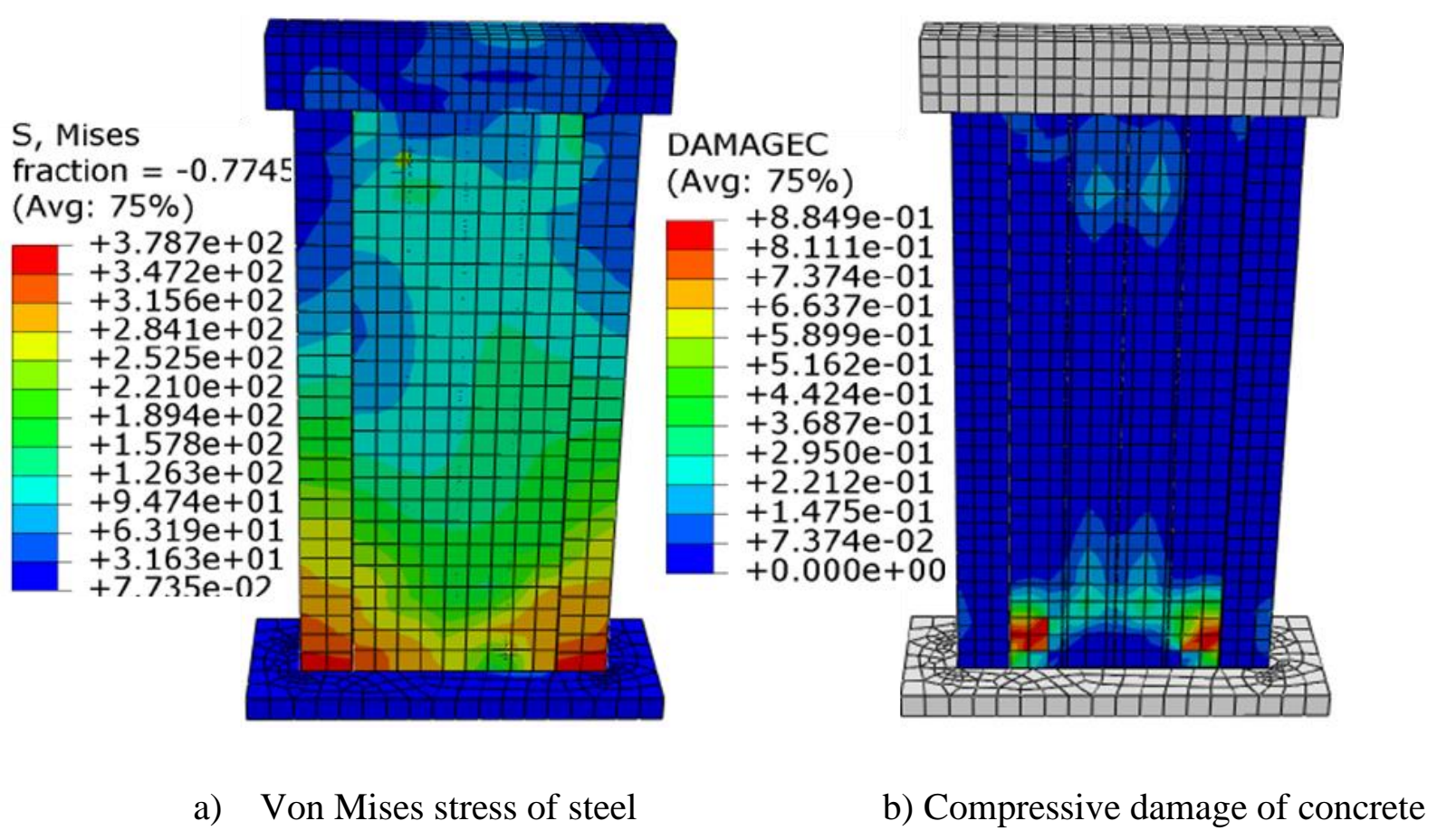

Figure 12. Stress contour in steel plate and damage of concrete at $0.75 \%$ 


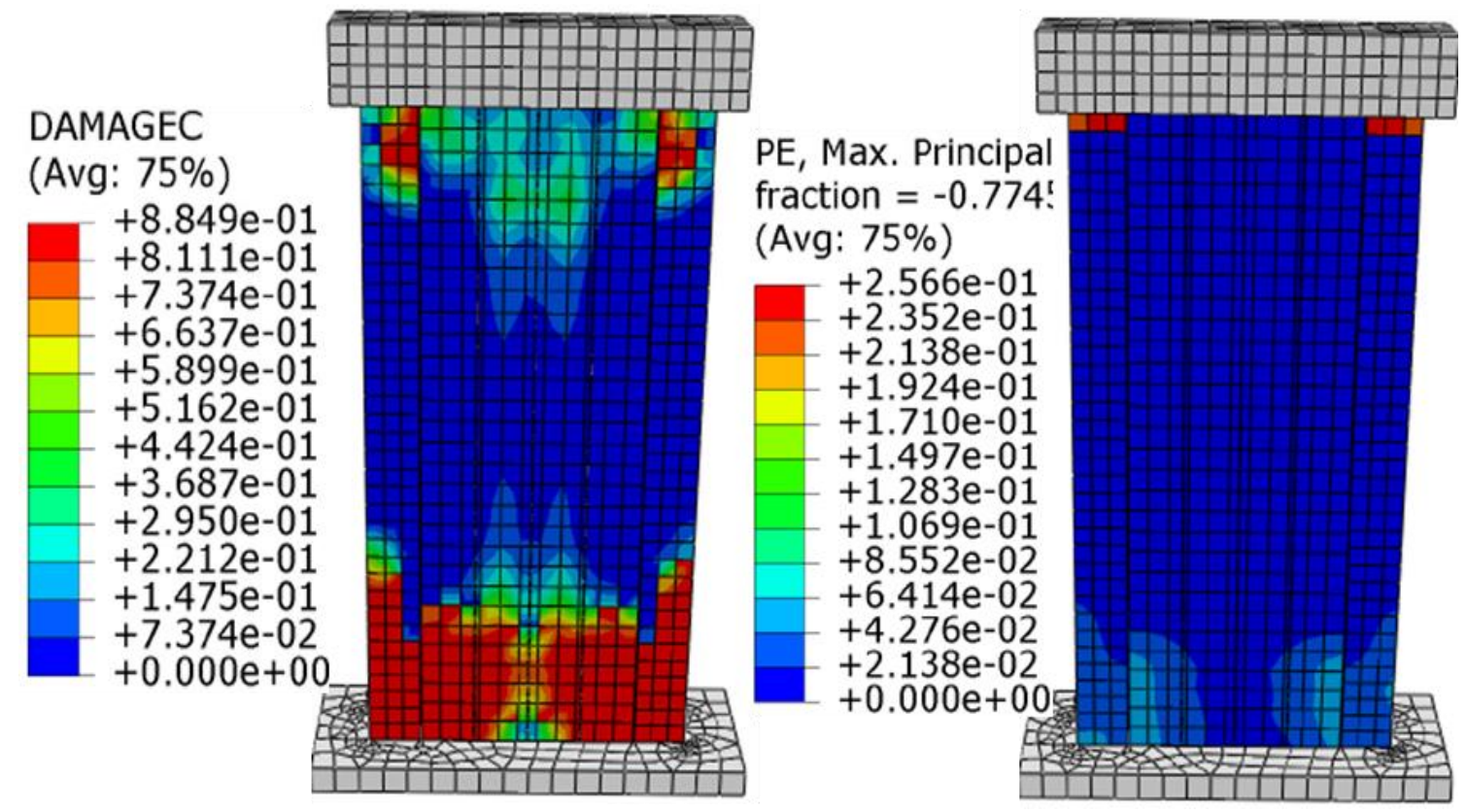

a) Compressive damage of concrete

b) Maximum Principal Plastic Strain

Figure 13. Damage and strain of concrete at $1.5 \%$ drift ratio of GS11-C70 specimen

\section{Stiffness Degradation}

Stiffness degradation is the damaged of materials in structures due to energy dissipation. In this study the cause of stiffness degradation of the composite shear wall is the cyclic loading which damages the concrete component through compressive and tensile loading and the yield of steel plate component. Stiffness degradation is evaluated using Equation 5 (Nie et al., 2008).

$$
K_{j}=\frac{\sum_{i=1}^{n_{j}} P_{j}^{i}}{\sum_{i=1}^{n_{j}} \delta_{j}^{i}}
$$

Where $\quad K_{j}$ is the cyclic stiffness

$\delta_{j}^{i}$ is the maximum top displacement at $\mathrm{i}$ cycle of the $\mathrm{j}$ loading level,

$P_{j}^{i}$ is the lateral force corresponding to $\delta_{j}^{i}$,

$n_{j}$ is the cyclic number of the $\mathrm{j}$ loading level

Based on the above equation, stiffness degradation for each specimen is calculated using displacement and corresponding load in both directions (+\& -) of the first cycle out of two reversal cycles at each drift ratio. The rate of stiffness degradation of the GS1 series specimens has shown gentile slope obtained using Equation 5 above. Relative to the control specimen, GS11-C70 and GS12-C60 exhibited better stiffness up to 1.5\% drift ratio which shows that higher concrete grade used in composite shear wall create stiff wall and the least stiff specimen of the GS1 series is GS13-C45. Similarly, the GS2 series specimens exhibited highest stiffness by GS21-S355 specimen with the highest steel strength which indicates that a composite shear wall with higher steel plate strength and other parameters constant has better stiffness relatively. The rate of stiffness degradation is lower for GS21-S355 even 
better than the control specimen which is the best specimen of all with respect to stiffness. The least stiff of GS2 series is GS23-S245 specimen as expected due to the lowest steel plate grade used for this specimen which totally lost its in plane lateral stiffness at $1.25 \%$ drift ratio while other specimens of the group and the control specimen have large stiffness at the drift ratio.

The stiffness degradation of the GS3 series which have identical rate of degradation up to $1.5 \%$ drift ratio which indicate that the total number of tie constrains have no effect on the stiffness due to the confinement of the concrete which has significant effect on the composite action than that of tie constraint in this study. The degradation of stiffness of GS3 series is similar from the initial to the end of the drift ratios of the first cycle out of two reversals cyclic loading. However, the stiffness degradation of the GS3 series relative to the control specimen differed beyond $1 \%$ drift ratio with very limited magnitude. The GS33TC248 has totally lost its stiffness at $1.5 \%$ drift ratio while other specimen of the GS3 series show significant stiffness up to $1.75 \%$ drift ratio including the control specimen. The GS4 series specimens of this study had shown stiffness degradation relative to the control specimen and to each other which can be describes as GS41-ST6.5 had relatively higher stiffness up to $0.75 \%$ drift ratio than the control specimen and other corresponding specimens. However, the variation of thickness of steel plate used in composite shear wall has limited effect on stiffness degradation as expected.

\section{Ductility}

A structure that can undergo large deformation without failing described as ductile; a ductile structure's ability to dissipate energy during earthquake is advantageous, as it will keep deformation without reaching ultimate failure or collapse as described by Anderiw O'Donnell \& Julia Krezel, 2006. In this section, ductility of all specimen are evaluated using ductility factor $\left(\mu_{\Delta}\right)$ which is calculated by applying Equation 6 according to Committee EuroInternational Du Beton (1996) by taking the yield displacement $\left(\Delta_{y}\right)$ as lateral displacement at $80 \%$ of ultimate load (maximum load) at the ascending part \& failure displacement $\left(\Delta_{f}\right)$ as lateral displacement at $80 \%$ of ultimate load (maximum load) at the descending part of the envelop curves presented under Load-Displacement Behavior.

$$
\mu_{\Delta}=\frac{\Delta_{f}}{\Delta_{y}}
$$

The ductility factors for all specimens were calculated and presented in table 4.3 for comparison of each specimen with the control specimen. The ductility factor of GS11-70 and GS12-C60 specimens are higher by $4.97 \%$ \& 9.35\% respectively from the control specimen; this indicates that; a composite shear wall with relatively higher concrete grade has less ductility property which is relatively brittle. However, GS13-C45 specimen exhibited lower ductility factor from the control specimen by $10.83 \%$ which shows that when grade of concrete used in composite shear wall is dropped from certain limit, the ductility property is also affected. Similarly, the grade of steel plate used in composite shear wall had significant effect on the ductile property. The GS21-S355 has shown an increment of ductility factor by $7.12 \%$ from the control specimen while the GS23-S245 exhibited a drop of ductility factor by $19.83 \%$. GS22S265 has equivalent ductility factor to the control specimen as expected due to close steel grade used for both specimens. 
Table 7. Ductility Factor

\begin{tabular}{|c|c|c|c|c|c|c|c|c|}
\hline \multirow{2}{*}{ Specimen } & \multicolumn{2}{|c|}{$\begin{array}{c}\text { Yield } \\
\text { Displacement }\end{array}$} & \multicolumn{2}{|c|}{$\begin{array}{c}\text { Ultimate } \\
\text { Displacement }\end{array}$} & \multicolumn{2}{|c|}{$\begin{array}{l}\text { Ductility } \\
\text { Factor }\end{array}$} & \multirow{2}{*}{$\begin{array}{c}\text { Lowest } \\
\text { Ductility } \\
\text { Factor }\end{array}$} & \multirow{2}{*}{$\begin{array}{c}\text { Change } \\
\text { in } \\
\text { Ductility } \\
\text { Factor }\end{array}$} \\
\hline & $(+)$ & $(-)$ & $(+)$ & $(-)$ & $(+)$ & $(-)$ & & \\
\hline Control & 9.88 & -9.65 & 42.24 & -43.29 & 4.28 & 4.48 & 4.28 & \\
\hline GS11-C70 & 9.41 & -9.26 & 43.20 & -41.56 & 4.59 & 4.49 & 4.49 & $4.97 \%$ \\
\hline GS12-C60 & 9.52 & -9.56 & 44.91 & -44.71 & 4.72 & 4.68 & 4.68 & $9.35 \%$ \\
\hline GS13-C45 & 10.05 & -9.87 & 44.31 & -37.66 & 4.41 & 3.81 & 3.81 & $-10.83 \%$ \\
\hline GS21-S355 & 11.42 & -10.96 & 52.30 & -53.20 & 4.58 & 4.85 & 4.58 & $7.12 \%$ \\
\hline GS22-S265 & 9.79 & -9.73 & 44.16 & -41.85 & 4.51 & 4.30 & 4.30 & $0.55 \%$ \\
\hline GS23-S245 & 9.18 & -8.91 & 31.48 & -31.24 & 3.43 & 3.51 & 3.43 & $-19.83 \%$ \\
\hline GS31-TC660 & 9.69 & -9.43 & 44.69 & -41.37 & 4.61 & 4.39 & 4.39 & $2.56 \%$ \\
\hline GS32-TC440 & 9.62 & -9.49 & 44.77 & -43.16 & 4.65 & 4.55 & 4.55 & $6.31 \%$ \\
\hline GS33-TC280 & 9.64 & -9.55 & 37.46 & -35.57 & 3.88 & 3.73 & 3.73 & $-12.90 \%$ \\
\hline GS41-ST6.5 & 9.48 & -9.00 & 42.94 & -38.41 & 4.53 & 4.27 & 4.27 & $-0.21 \%$ \\
\hline GS42-ST4 & 9.50 & -9.18 & 44.93 & -40.10 & 4.73 & 4.37 & 4.37 & $2.14 \%$ \\
\hline GS43-ST3 & 9.68 & -9.14 & 42.93 & -41.64 & 4.44 & 4.56 & 4.44 & $3.73 \%$ \\
\hline
\end{tabular}

The total number of tie constraints on the ductility property of the composite shear wall is observed as the drop of tie constraints from control specimen increases the ductility factor up to the total tie constraints of 440 of GS32-TC440 specimen.

The effect of steel plate thickness on the ductility property of composite shear wall expected but in this study the difference in steel plate thickness of GS4 series specimen from the control specimen is very limited and the result of the ductility factors are accordingly equivalent.

\section{Energy Dissipation Capacity}

Energy dissipation capacity of structures under cyclic loading is important aspect that shall be considered in studying behavior of lateral load resisting systems. Imparted energy to structures through cyclic loading can be computed for each cycle as the area enclosed by the lateral loaddisplacement hysteresis loop for the cycle. In this study the energy dissipation capacity of composite shear wall specimens under cyclic loading were evaluated based on the results obtained from the analysis software (ABAQUS) and presented at different drift ratios for each group of specimens. As compared to the control specimen, the GS11-C70, GS12-C60 and GS13-C45 of group 1 series exhibited similar energy dissipation up to 1\% drift ratio and beyond that the dissipated energy up to $1.7 \%$ drift ratio differ at all drift ratios; specimen with higher grade of concrete relatively dissipated more energy and vice versa. 
The GS2 series with steel grade variation has shown that specimen with higher steel grade has good energy dissipation capacity. GS21-S355 specimen has exhibited the highest energy dissipated during the cyclic loading relative to all specimens. This indicate that higher grade of steel plate used in composite shear wall specimen has ability to dissipate more energy than the corresponding specimen with lower steel plate.

The GS3 series specimens with variable total number of tie constraints used between concrete and steel plate as studs to create composite action have shown different dissipated energy beyond $1 \%$ drift ratio. The more components gain composite action in composite shear wall, the better the dissipated energy according to the findings in this study. The GS33-TC248 exhibited significant reduction of dissipated energy during the whole cyclic loading as compared to the control specimen.

The energy dissipated in GS4 series specimens indicates that the steel plate thickness used in composite shear wall has an effect on the capacity of a specimen to absorb imparted energy due to cyclic loading. Similar to other groups of specimens, the GS4 series has shown significant difference in dissipated energy beyond $1 \%$ drift ratio.

\section{Conclusions and Recommendations}

\section{General}

Finite element analysis of steel-concrete composite shear wall under cyclic loading was conducted for thirteen specimens with variable parameters to observe behavior of composite shear wall under cyclic loading as well as to identify critical parameters. Accordingly, the loaddisplacement behavior, modes of failure, stiffness degradation, and ductility characteristics of specimens, energy dissipation capacity and plastic strain in steel plates were evaluated and discussed in previous sections of this study and now conclusions are drawn from the investigations and recommendations for the future works are presented in the following sections.

\section{Conclusions}

The following conclusions are drawn from the investigation of this study:

- Concrete grade is observed as critical parameter for steel-concrete composite shear wall performance under cyclic loading. High strength concrete used in composite shear wall is relatively good in resisting concrete compressive damage which is one cause for early plastic strain development at the bottom of composite shear wall and capable to sustain under high axial load relatively during lateral cyclic loading.

- Lateral load capacity is directly related to concrete grade used in composite shear wall as well as stiffness of composite shear wall is directly related to concrete grade up to the maximum load capacity which is in average up to $0.75 \%$ drift ratio. However, the ductility property of the composite shear wall in this study is inversely related to the concrete grade up to C60 (60MPa).

- Nearly $50 \%$ reduction of total number of tie constraints from control specimen used between steel and concrete materials considered as studs to create composite action has no significant effect on lateral load capacity, ductility, and stiffness in steel plate of the composite shear wall.

- Variable thickness of steel plate used in GS4 series has limited effect on the load capacity, ductility, stiffness, total dissipated energy of the composite shear walls specimens.

- There is no local buckling observed on the steel plate surface during the whole loading steps due to properly arranged intermediate stiffeners and provided tie constraints as studs. This indicates that the concrete and steel plate work together and compatible. 


\section{Recommendations}

Further investigation on the behavior of composite shear wall under cyclic loading is important for the use of efficient design requirements and recommendation. Accordingly, in this study it is confirmed that certain subjects need detail approach $\&$ here the following recommendations are pointed out for future studies on composite shear wall:

- In this study a single shear span ratio of 2 is considered for the parametric study but, others can work on different shear span ratios.

- Further studies on composite shear wall with different shapes of boundary elements is another recommendation for the future works

- In this study, the composite action between concrete and steel plate is created by tie constraints which is assumed as perfect bond between them. However, it is recommended to consider slippage between the two materials to get better simulation of response which is another point for the future studies.

\section{References}

[1] Q. Zhao, A. Astaneh-Asl, and M. Asce, "Cyclic behavior of traditional and innovative composite shear walls," Journal of Structural Engineering, Vol. 130, No. 2, pp. 271-284, 2004. doi: 10.1061/(ASCE)0733-9445(2004)130:2(271)

[2] K.A.S. Susantha, H. Ge, and T. Usami, "Uniaxial stress-stain relationship of concrete confined by various shaped steel tubes," Journal of Engineering Structures, Vol. 23, pp. 1331-1347, 2001 [Online]. Available: http:// www.elsevier.com/locate/engstruct

[3] A. Belarbi, L. Zhang, and T.T.C. Hsu, "Constitutive laws of reinforced concrete membrane elements," Paper presented at $11^{\text {th }}$ International Conference on Earthquake Engineering, Elsevier Science LTD, Houston, United States, 1994.

[4] J.G. Nie, H.S. Hu, J.S. Fan, M.X. Tao, S.Y. Li, and F. Liu, "Experimental study on seismic behavior of high strength concrete filled double steel plate composite walls," Journal of Constructional Steel Research, Vol. 88, pp. 207-218, 2013 [Online]. Available: $\mathrm{http} / / \mathrm{www}$. sciencedirect.com/science/journal/0143974x

[5] K.M.A. Hossain, and H.D. Wright, "Experimental and theoretical behavior of composite walling under in-plane shear," Journal of Constructional Steel Research, Vol. 60, pp. 59-83, 2004 [Online]. Available: http://www.sciencedirect.com

[6] D. Dan, A. Fabian, and V. Stoian, "Theoretical and experimental study on composite steel concrete shear walls with vertical steel encased profiles," Journal of Constructional Steel Research, Vol. 67, pp. 800-813, 2011 [Online]. Available: http://www.elsevier.com/locate/jcsr

[7] ACI Committee, Building Code Requirements for Structural Concrete, ACI 318-19, Farmington Hills, Michigan, United States, 2019. Doi: 10.14359/51716937

[8] J. Li, Y. Wang, Z. Lu, and J. Li, "Experimental study and numerical simulation of a laminated reinforced concrete shear wall with a vertical seam," Journal of Applied Science, Vol. 629, 2017 [Online]. Available: http://www.mdpi.com/journal/applsci

[9] Dassault Systèmes Simulia Corp., Abaqus Analysis User's Guide, Vol. 1-5, United States, 2014 [Online]. Available: http://www.3ds.com/support-training/

[10] K.T. Kweenisky, N. Pratiwi, and P.K. Wijaya "The collapse analysis of the lateral-torsional buckling of I-shaped stepped steel beams," Journal of the Civil Engineering Forum, Vol. 6 No. 3, 2020 [Online]. Available: http://www.jurnal.ugm.ac.id/jcef/article/56934 